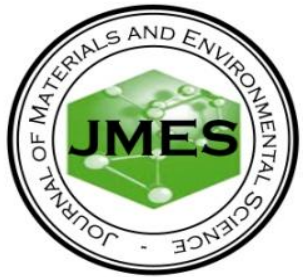

\title{
Interfacial Indentation Test for the Study of Reinforcement bar/concrete matrix Adhesion in High Performance Self Compacting Concretes
}

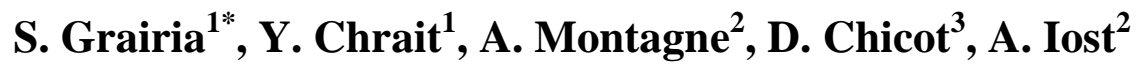 \\ 1. Laboratoirede Génie Civil et Hydraulique - LGCH, Université 8 mai 45, Guelma, Algérie. \\ 2. Arts et Métiers Paris Tech, MSMP, ENSAM, 8 Boulevard Louis XIV, Lille, France. \\ 3. Univ. Lille, FRE 3723-LML-Laboratoire de Mécanique de Lille, Lille, France.
}

\author{
Received 25 Mar2017, \\ Revised 26 May 2017, \\ Accepted 30 May 2017 \\ Keywords \\ $\checkmark$ Interfacial indentation \\ test; \\ $\checkmark$ apparent interfacial \\ toughness; \\ $\checkmark$ Adhesion, \\ $\checkmark$ High performance; \\ $\checkmark$ Self-compacting \\ concrete; \\ $\checkmark$ Microstructure.
}

S.Grairia s.grairia@hotmail.fr $+213772789809$

\begin{abstract}
The interfacial indentation test is experimented for the first time in order to characterize the adhesion between the concrete and its steel reinforcement. This technique, developed to estimate the adhesion of thick coatings (thermal barrier, plasma torch deposits, etc.), is used here to create and propagate a crack along the concrete/reinforcement interface. The length of this crack makes it possible to calculate an apparent interfacial toughness which can then be linked to the concrete/reinforcement adhesion, and therefore to the resistance of the elaborate structure. The mechanical properties, hardness and Young's modulus of the various constituents were determined from indentation tests, and micro cracks at the concrete/reinforcement interface are generated by Vickers macro-hardness tests using indentation loads ranging from 300 to $1200 \mathrm{~N}$. The properties of three concretes are compared: a high-performance vibrated concrete HPVC (VC54) and two high-performance self-compacting concretes HPSCCs (SCC54 and SCC62), both developed in the laboratory. The adhesion in terms of apparent interfacial toughness of (SCC54) was found to be greater by $9.17 \%$ than that of (VC54) with the same compressive strength. This improvement in bond behavior of SCC against that of vibrated concrete (VC) can be attributed to the higher amount of fine aggregates and higher workability, which results in a better containment of the reinforcement bars. The results obtained by this test are in agreement with those of conventional pull-outs tests while being easier to realize, and we propose its use in order to characterize the adhesion between the concrete and its metallic reinforcement.
\end{abstract}

\section{Introduction}

The adhesion between the concrete and its metallic reinforcement is a fundamental property that characterizes the level of load that can undergo a reinforced concrete structure, and thus allows estimating its possible degradation and therefore its residual lifetime. We note that the steel works well as reinforcement for concrete because it bonds well with concrete and this bond strength, which characterizes the adhesion, is proportional to the contact surface of the steel to the concrete. The adhesion greatly varies with changes in mix design and grade of cement used and by providing intensive heat curing, high early adhesion can be achieved [1]. Moreover, concretes compressive strength, water to binder (w/b) ratio, bar diameter, concrete cover, embedded length, and pre-flexural crack length also affect this adhesion [2].

There are 3 ways in which cement concrete is bonded to a steel reinforcement: (i) adhesion between concrete and steel bars, (ii) mechanical Interlock through ribs of steel bar and (iii) chemical reaction between steel and concrete [3]. The interfacial bond strength, which always characterizes the adhesion between the steel bar and the matrix in reinforced concrete, is generally estimated by a bending test (Beam test) or pull-out test defined in ISO 14916 standards [4]. These tests are often controversial, sensitive to experimental conditions, and not very reproducible since the dispersion of the results can reach 50\% in inter-laboratory comparisons [5].In composite materials, constituents and interactions (adhesion) between them play an important role in global behavior of final material. In this regard, numerous researches have been conducted all over the world to clarify this adhesion.

VC and SCC have a substantially different mix design; especially regarding the amount and proportion of coarse aggregates, water to binder (w/b) ratio and fine material, which inevitably results in distinct adhesion behavior. 
In order to quantify this difference, many experimental investigations through the world are performed in this senseby means of different type of tests such as Three Point Bending Test (3PBT) or pull-out tests (POT). For instance, according to literature results, a study by Aslani \& Nejadi [6] presented a bond strength model based on the experimental results from eight recent investigations on SCC and VC concrete specimens. The comparisons were based upon models of structural sections using pull-out tests to measure bond between the steel reinforcing bar and concrete. It was found that the SCC had slightly higher bond strengths than VC.

Similarly, Arezoumandi et al. [7] in their comparison performed between results of their study with a bond database of Conventional Concrete (CC) or Vibrated Concrete (VC) specimens, they found that Self Compacting Concrete (SCC) beams possess comparable or slightly greater bond strength than Vibrated Concrete (VC) beams. Furthermore, they also found that High Performance Self Compacting Concrete (HPSCC) possess reinforcement bond strength (i.e. adhesion) comparable or slightly greater than High Performance Vibrated Concrete (HPVC). Further research in Ghent University by Helincks et al. [8] used an experimental program to investigate the bond performance of powder-type SCC. Pull out tests were carried out in accordance with RILEM, RC6, Part 2 recommendations. In total 72 pull specimens were tested, cast with different concrete mixtures and rebar diameter $(8,12,16$ and $20 \mathrm{~mm})$. It was found that $\mathrm{SC}$ showed normalized characteristic bond strength values as high as or higher than equivalent VC.

On the other hand, as has been pointed out in the literature that in recent years, researchers have paid more attention to the characterization of the steel reinforcement-SCC adhesion using different methods, but in addition, all the benefits that the Method of interfacial indentation has for this type of characterization, the researches in this respect were too rare. In this regard, due to the lack of knowledge on the determination of adhesion parameters with indentation tests, the use of existing related design equations, which are valid for other types of fragile materials, could be used to determine the apparent interfacial toughness which characterizes the adhesion of these self-Compacting concretes with their steel reinforcement.

The objective of this study is to use the interfacial indentation test to quantify the adhesion between the concrete and its metallic reinforcement. For this we design and characterize two types of concrete: High performance self-compacting concrete HPSCC, i.e. Self-Compacting Concretes with compressive strengths of $54 \mathrm{MPa}$ and 62 MPa (SCC54 and SCC62), and high-performance vibrated concrete HPVC, i.e. Vibrated Concrete with compressive strength of $54 \mathrm{MPa}$ (VC54) which will serve as a reference. Specimens, with steel reinforcements coated with these concretes, are used to characterize the resistance of the (SCC54/Steel), (SCC62/Steel) and (VC54/Steel) interfaces to the resistance to propagation of the cracks.

The behavior of these three interfaces is compared, and also the advantages of the interfacial indentation test compared to the conventional tests used to characterize the adhesion between concrete and steel. We describe in a first paragraph the materials used, their chemical analysis, their physical and mechanical properties, as well as the mode of production of the specimens and the experimental techniques of characterization. The following paragraph presents the results obtained by the interfacial indentation test and compares them with those of the conventional pull-out tests found in literature. The best properties obtained for self-compacting concrete are explained in relation to its composition and method of production. Based on the results, VC's and SCC's adhesion, such as apparent interfacial toughness, are calculated and compared.

In conclusion, the indentation test showed clear advantages over the conventional pullout test and also shows once again its aptitude to study the adhesion of concrete/steel bar reinforcement couple.

\section{Materials, Elaboration and Experimental Methods}

\subsection{Raw materials}

Two types of concrete to be studied are prepared from the following constituents:

- A composed Portland cement CPJ-CEM II / A 42.5, of Algerian origin, manufactured by the cement factory of Hjar Essoud (Skikda-Algeria) with a compressive strength of $42.5 \mathrm{MPa}$ having good sulphate resistance and low heat of hydration according to NF EN 197-1 standard [9]. The physical properties and chemical analyzes of this cement are presented in table 1.

Table1: Physical properties and chemical analysis (w/w \%) of cement.

\begin{tabular}{|c|c|c|c|c|c|c|c|c|c|c|c|}
\hline \multicolumn{1}{|c|}{ Physical properties } & \multicolumn{10}{|c|}{ Chemical analysis $(\%)$} \\
\hline $\begin{array}{c}\text { Density } \\
\left(\mathrm{t} / \mathrm{m}^{3}\right)\end{array}$ & $\begin{array}{c}\text { Specific surface- } \\
\text { BET }\left(\mathrm{m}^{2} / \mathrm{g}\right)\end{array}$ & $\mathrm{SiO}_{2}$ & $\mathrm{CaO}$ & $\begin{array}{l}\mathrm{Al}_{2} \mathrm{O} \\
3\end{array}$ & $\mathrm{SO}_{3}$ & $\mathrm{Fe}_{2} \mathrm{O}_{3}$ & $\mathrm{~K}_{2} \mathrm{O}$ & $\mathrm{Na}_{2} \mathrm{O}$ & $\mathrm{MgO}$ & $\mathrm{LAf}$ & $\mathrm{I} \mathrm{R}$ \\
\hline 3.100 & 0.3480 & 24.92 & 58.6 & 6.58 & 2.17 & 3.65 & 0.85 & 0.08 & 1.21 & 1.7 & 0.23 \\
\hline
\end{tabular}

*Chemical analysis of material (ex.cement) expressed asw/w (\%) = weight of chemical element $\left(\mathrm{ex} \mathrm{Fe}_{2} \mathrm{O}_{3}\right)$ in material (ex.cement)/total weight of this material (ex.cement) (\%).

*IR: Insoluble Residue, LAF: Loss At Fire. 
- The silica fume (Sf) (Medaplast HP) is used to replace $8.0 \%$ by mass of cement. Most standards and codes [10-11] recommend the use of this silica fume as an additive for the replacement of about $5-10 \%$ by mass of the cement. The incorporated silica fume is a pozzolan in the form of a very active fine powder. The chemical analysis and the physical properties of the silica fume used are shown in table 2.

Table 2: Physical properties and chemical analysis (w/w \%) of silica fume.

\begin{tabular}{|c|c|c|c|c|c|c|c|}
\hline \multicolumn{2}{|c|}{ Physical properties } & \multicolumn{5}{c|}{ Chemical analysis $(\%)$} \\
\hline Density $\left(\mathrm{t} / \mathrm{m}^{3}\right)$ & Specific surface - BET $\left(\mathrm{m}^{2} / \mathrm{g}\right)$ & $\mathrm{SiO}_{2}$ & $\mathrm{Al}_{2} \mathrm{O}_{3}$ & $\mathrm{SO}_{3}$ & $\mathrm{Fe}_{2} \mathrm{O}_{3}$ & $\mathrm{~K}_{2} \mathrm{O}$ & $\mathrm{Na}_{2} \mathrm{O}$ \\
\hline 1.07 & 21.7 & 92.1 & 0.25 & 0.36 & 0.79 & 0.96 & 0.17 \\
\hline
\end{tabular}

- The limestone powder (lp), having a calcium carbonate $(\mathrm{CaCO} 3)$ content of $97.6 \%$, with purity and great fineness, are introduced into the mixtures of self-compacting concretes in order to improve the plastic viscosity and achieving the required stability. The chemical analysis and the physical properties of these calcareous fillers are presented in table 3.

Table 3: Physical properties and mineralogical composition (w/w \%) of limestone powder.

\begin{tabular}{|c|c|c|c|c|c|c|}
\hline \multicolumn{3}{|c|}{ Physical properties } & \multicolumn{4}{c|}{ Mineral composition (\%) } \\
\hline $\begin{array}{c}\text { Density } \\
\left(\mathrm{t} / \mathrm{m}^{3}\right)\end{array}$ & $\begin{array}{c}\text { Specific surface- - BET } \\
\left(\mathrm{m}^{2} / \mathrm{g}\right)\end{array}$ & finesse modulus & $\mathrm{CaCO}_{3}$ & $\mathrm{SiO}_{2}$ & $\mathrm{MgO}$ & $\mathrm{Fe}_{2} \mathrm{O}_{3}$ \\
\hline 2.60 & 0.5226 & 0.19 & 97.62 & 0.81 & 0.78 & 0.08 \\
\hline
\end{tabular}

- Three nominal classes of crushed limestone aggregates (Ain Touta, Batna 05, Algeria) and a local sea sand are used for the production of all SCC and VC mixtures: sea sand (ss, 0/3 mm), Crushed sand (cs, 0/4 mm), small gravel (g1, 4/8 mm) and medium gravel $(\mathrm{g} 2,8 / 16 \mathrm{~mm})$. All appropriate corrections have been adopted in order for the aggregates to reach the surface-dry-saturated state according to EN 1097-6: 2000 [12]. The physical properties (bulk density, water absorption) of the aggregates used are presented in table 4.

Table 4: Physical properties of aggregates (calculated according to [11].

\begin{tabular}{|c|c|c|c|c|}
\hline aggregate Type & Sea sand (ss) & Crushed san (cs) & Small gravel (g1) & Medium gravel (g2) \\
\hline A.d $\left(\mathrm{t} / \mathrm{m}^{3}\right)$ & 2.67 & 2.52 & 2.64 & 2.63 \\
\hline W.a (\%) & 0.9 & 0.7 & 0.28 & 0.27 \\
\hline
\end{tabular}

*A.d: Apparent density on an oven dried basis (t/m3). W.a: Water absorption (\%).

The required fluidity of self-placing concretes is achieved by incorporating suitable doses of Medaflow superplasticizer polycarboxylate (pce) according to EN 934-2: 2009 [13].Super plasticizers are used to improve the fluidity of the concrete and reduce the amount of water to be added. This same super plasticizer is used for the production of mixtures of vibrated concrete.

\subsection{Proportions and used mixtures}

Self-compacting concrete consists of a binder (cement + calcareous fillers + a pozzolan type material, i.e. silica fume) and aggregates (sea sand, crushed sand, small gravel and medium gravel). The water to binder ratio (w/b) is equal to 0.35 (for SCC54) and 0.33 (for SCC62) by incorporation of $2.17 \%$ by mass of cement of superplasticizer (for both SCCs).The SCC is, according to its properties in the fresh state, a concrete that flows by only gravity effect, capable of completely filling the formwork with its reinforcement, its sheaths while maintaining its homogeneity. The vibrated concrete flows and compacts under the vibrations of a mechanical vibrator used when pouring the concrete into the formwork. It is designed on the basis of a typical composition used in the local construction industry. It represents mobility in an unconfined environment, described by the 70 $\mathrm{cm}$ slump flow test, obtained by incorporating $3.3 \%$ by mass of super plasticizer in the cement. VC is a reference mixture having a compressive strength of about $54 \mathrm{MPa}$. One of the two SCC which is theSCC54 is designed to have the same compressive strength as these VCs, by reducing the amount of the binder, resulting in an increased w/b ratio. The other which is the SCC62 is designed to have water to binder ratio less than that of the SCC54; the mixing proportions of SCC62, SCC54 and VC54 are summarized in table 5.

The dry materials are first introduced and kneaded. The water, then 30 seconds later the super plasticizer, are added gradually for 1 minute. The mixing is then carried out for 2 minutes in a planetary mixer. The properties of the fresh concrete were determined according to the standard by the tests: V-funnel, slump-flow and L-box for the SCC mixtures and by spreading test for The VC mixtures [14]. 
Table 5: Proportions of mixture of calcareous aggregates and super plasticizer ( $\mathrm{Sp}$ ) (in $\mathrm{kg} / \mathrm{m} 3$ ) used in the preparation of SCC54 andVC54.

\begin{tabular}{|c|c|c|c|c|c|c|c|c|c|c|}
\hline $\begin{array}{c}\text { Materials } \\
\left(\mathrm{kg} / \mathrm{m}^{3}\right)\end{array}$ & $\begin{array}{c}\text { CEM I } \\
42.5 \mathrm{~N}(\mathrm{c})\end{array}$ & ss & cs & $\mathrm{g} 1$ & $\mathrm{~g} 2$ & $\mathrm{Lp}$ & $\mathrm{Sf}$ & $\begin{array}{c}\text { Effective } \\
\text { water }\end{array}$ & Sp & (w/b) ratio \\
\hline (VC54) & 400 & 570 & 243 & 379 & 567 & - & - & 144 & 13.2 & 0.36 \\
\hline (SCC54) & 368 & 570 & 243 & 328 & 492 & 100 & 32 & 160 & 8 & 0.35 \\
\hline (SCC62) & 368 & 570 & 243 & 328 & 492 & 100 & 32 & 151 & 8 & 0.33 \\
\hline
\end{tabular}

*Lp: Limestone powder, Sf: Silica fume, $\mathbf{s p : ~ S u p e r ~ p l a s t i c i z e r , ~ w / b : ~ w a t e r ~ t o ~ b i n d e r ~ r a t i o . ~}$

The hardened properties were identified by the compressive strength $\left(f_{c, \text { cyl }}\right)$ at 28 days. $160 / 320 \mathrm{~mm}$ cylinders are molded and then demolded after 1 day, sealed and stored at $\left(20 \pm 2{ }^{\circ} \mathrm{C}, 95 \pm 5 \%\right.$ relative humidity) until testing. The mean values of the properties of fresh and hardened concrete are summarized in table 6 for all mixtures, as well as the recommended theoretical values [15].

Table 6: Properties and workability of fresh and hardened concretes and EFNARC Recommendations [15].

\begin{tabular}{|c|c|c|c|c|c|c|}
\hline Properties & $\begin{array}{c}\text { Sinking } \\
(\mathrm{mm})\end{array}$ & $\begin{array}{c}\text { Spreading } \\
(\mathrm{mm})\end{array}$ & $\begin{array}{c}\mathrm{L}-\text { box }(\mathrm{s}) \\
\left(\mathrm{h}_{2} / \mathrm{h}_{1}\right)\end{array}$ & $\begin{array}{c}\text { V-funnel } \\
(\mathrm{s})\end{array}$ & $\begin{array}{c}\mathrm{fc}_{28, \mathrm{cyl}} \\
(\mathrm{MPa})\end{array}$ & $\begin{array}{c}\mathrm{f}_{28, \mathrm{cub}} \\
(\mathrm{MPa})\end{array}$ \\
\hline (VC54) & 70 & - & - & - & $53.6 \pm 1.6$ & 59.37 \\
\hline (SCC54) & - & 695 & 0.84 & 10.4 & $54.3 \pm 2.2$ & 60.33 \\
\hline (SCC62) & - & 675 & 0.81 & 11.7 & $61.7 \pm 3.0$ & 68.55 \\
\hline EFNARC & - & $650-800$ & $>\mathrm{à} 0.8$ & $(8-14)$ & - & - \\
\hline
\end{tabular}

\subsection{Reinforcing steel}

The reinforced bars of steel reinforcement showed in figure (1-a) of nominal average diameter $16 \mathrm{~mm}$ and grade BE500S, conforming to EN 10080 (2005) [16], are introduced into the concrete samples of the figure(1-b) in order to evaluate the adhesion characteristics.

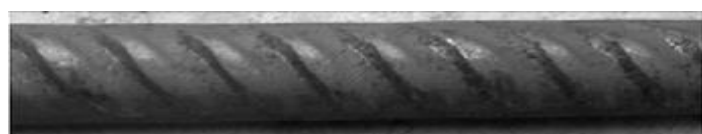

a)

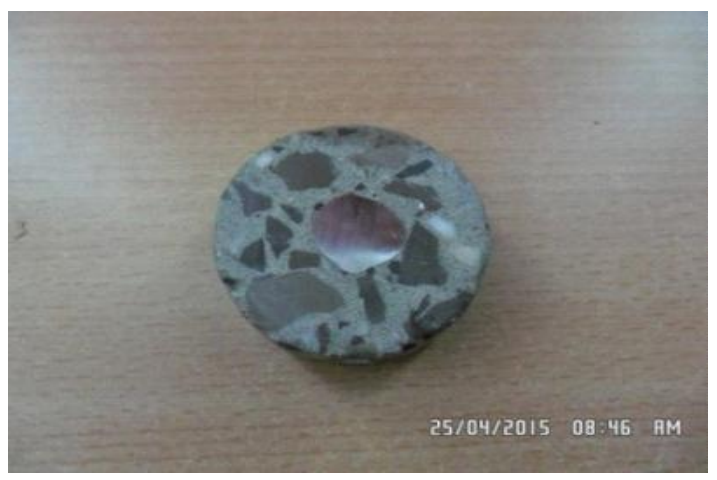

b)

Figure 1: Rebar of steel type BE500S, a)of nominal diameter $16 \mathrm{~mm}$ and b) the same bar inserted into a $45 \mathrm{~mm}$ diameter concrete matrix used for the interfacial indentation test.

A typical steel bar has two rows of transverse ribs uniformly distributed over the circumference and spaced in the long direction of the bar. A steel reinforcement bar was examined and tested in the laboratory to confirm the manufacturer's technical specifications with respect to diameter, cross-section, mass and mechanical properties (table7).

Table7: Geometric and mechanical properties of steel reinforcing bars[16].

\begin{tabular}{|c|c|c|c|c|}
\hline Parameter & Symbol & Units & $\begin{array}{c}\text { (Standard) values } \\
\text { (Average) }\end{array}$ & $\begin{array}{c}\text { Measured values } \\
\text { (Average) }\end{array}$ \\
\hline Diameter & $\mathrm{d}$ & $\mathrm{mm}$ & 16 & 15.93 \\
\hline Section & $\mathrm{An}$ & $\mathrm{mm}^{2}$ & 201 & 199.33 \\
\hline Mass & $\mathrm{M}$ & $\mathrm{kg} / \mathrm{m}$ & 1.58 & 1.56 \\
\hline Limit of Elasticity & $\mathrm{Re}$ & $\mathrm{MPa}$ & $485-650$ & 536 \\
\hline Maximum resistance & $\mathrm{Rm}$ & $\mathrm{MPa}$ & $(1.13-1.38) . \mathrm{Re}$ & 651 \\
\hline
\end{tabular}

\subsection{Samples preparation}

The samples preparation used for the mechanical characterization tests must be treated in order to avoid an excessive dispersion of the results [17]. Each coated steel bar is previously cleaned to ensure 
proper bonding with the concrete. For VC mixtures, the concrete is cast and compacted using conventional hand vibrators. The SCC mixtures are poured into a formwork of $100 x .100 \mathrm{~mm}^{2}$ section which is filled over a length of $1200 \mathrm{~mm}$ without vibration. The stripping is carried out one day after the casting and the reinforced concrete elements are immediately put in water for curing for 28 days. Samples for the apparent interfacial toughness study are extracted from the middle part of the reinforced concrete element. Small samples (about $45 \mathrm{~mm}$ in diameter and $22 \mathrm{~mm}$ high) containing a single steel bar in the center are then cut from the taken samples using a diamond saw. After demolding elements, the surface quality of self-compacting concrete samples is better than that of the vibrated concrete. This observation, also noted by other authors [18], shows the excellent filling capacity of SCCs, even for elements that require only very small amounts of concrete.

\subsection{Micro structural analysis}

Scanning electron microscopy (SEM) images were made on the fractured surfaces at the concrete/steel interface on the cementitious material side to examine the failure modes of the interface.

\subsection{Compressive test:}

For each concrete mix, four standard cylinders with a diameter of $160 \mathrm{~mm}$ and a height of $320 \mathrm{~mm}$ were cast into steel molds and then cured under ambient laboratory conditions $\left(20 \pm 2{ }^{\circ} \mathrm{C}, 95 \pm 5 \%\right.$ relative humidity). At the end of the curing period ( 28 days), these test pieces are tested on a hydraulic servo pressure frame in accordance with EN 12390-4: 2009 [19] to determine the average compressive strength, $\mathrm{f}_{\text {ccyl, }}$ and the corresponding standard deviation according to EN 12390-3: 2009 [20]. The results of the compressive strength are given in table 6 .

\subsection{Nanoindentation Tests (Grid Indentation Technique):}

Grid indentation involves the application of a large array of nanoindentation experiments, each with a characteristic indentation depth, $\mathrm{h}$, which elicits a mechanical response from a subsurface microvolume (figure.4-b). Developed at the Massachusetts Institute of Technology (MIT), its application has been extended to evaluation of nanomechanical properties of heterogeneous materials such as cementitious materials, bones, and shales [21].

From the simultaneous measurement of indentation load (P)and displacement (h), elasticity modulus (E) and hardness $(\mathrm{H})$ can be computed [22] at each point.

If, on the other hand, $\mathrm{h}_{\max }$ is greater than approximately $\mathrm{D} / 10$, then a composite mechanical response of multiple phases will inevitably be observed (figures.4-b and 4-c).

In this work, nanoindentation was performed over a grid of $10 \times 10$ points, evenly spaced by $150 \mu \mathrm{m}$. During each test, the load was linearly increased up to a maximum load of $650 \mathrm{mN}$ in $10 \mathrm{~s}$, kept constant for $5 \mathrm{~s}$, and linearly decreased in $10 \mathrm{~s}$.

The nanoindentation experiments of SCC and VC matrices have been performed on a Nano-Indenter XP TM (MTS Nano Instruments) employing a Berkovich diamond indenter with a load and depth sensing indentation mode .All measurements were performed at room temperature. In Load and depth sensing indentation mode, indentation area of specimens were selected randomly.

\subsection{Interfacial indentation test}

Cylindrical samples with a diameter of $48 \mathrm{~mm}$ and a height of $22 \mathrm{~mm}$, having a steel reinforcing bar $16 \mathrm{~mm}$ in diameter at their center, are manually polished using abrasive papers of grades 40, 120 up to 1200,then using diamonded paste with a grain diameter of $1 \mu \mathrm{m}$ up to a height of $18 \mathrm{~mm}$ in order to eliminate the defects and the residual stresses caused by the sawing (figure. 1-b).The indentation test involves applying a diamond Vickers pyramidal indenter at the two materials interface so as to generate a crack that propagates along that Interface as it is shown schematically in figure.2-a). This test is carried out using a Zwick ZHU instrumented indentation machine which can be used to apply loads between 5 and $2500 \mathrm{~N}$ and to record the load-displacement curves (figure.4-a).

The optical system connected to the hardness device makes it possible to aim with very good precision the interface between the concrete and the steel reinforcement. During the tests, loads P between 100and 2500N are applied to each sample type at a constant speed of $2 \mathrm{P} / \mathrm{min}$ (in $\mathrm{N} / \mathrm{min}$ ). The maximum load is maintained constant for 30 seconds and the imprints (diagonal 2d) and the cracks (length a) are observed and measured with the optical system of the apparatus immediately after unloading. The measurement of the cracks formed at the indented interface is used to evaluate the adhesion between the concrete and the steel bar by means of the apparent interfacial toughness, Kca. This method which has been originally developed by Chicot et al. [23, 24] 
requires indentations to be performed at least at three different loading levels, with five indentations for each level, to determine an average crack length.

These tests are used to evaluate the adhesion between a thick coating and its substrate such as thermal barrier materials, plasma torch deposits $[23,24,25]$. In a bi-logarithmic frame, the length of crack (a) varies linearly with the applied load, thus giving the so-called crack line. In the same system of axes, Chicot et al. represent the variation of the half-diagonal of the impression (d) with the applied load (P) (figure 2-c). In its principle, this methodology consists in applying a Vickers indenter under a given load in the plan of the interface between two materials. The objective is to create and propagate a crack in this interfacial plan as it is shown schematically in figure (2-a) and (2-b).

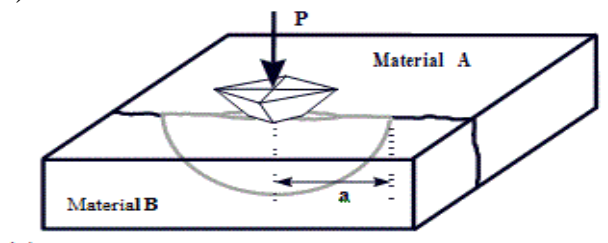

(a)

(b)

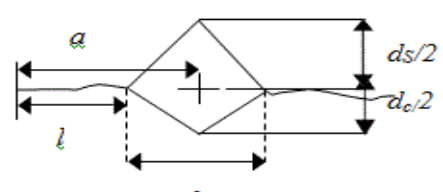

$d i$

1. Logarithm of Vickers hardness half diagonal $(d / 2)$

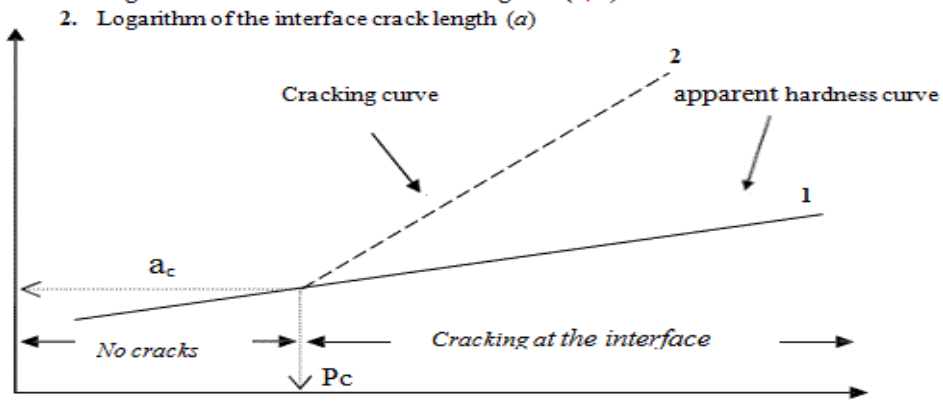

(c)

Logarithm of Vickers applied load $(P)$

Figure 2: a) Schematic illustration of an interfacial indentation test showing the crack propagation in the plan of the interface, b) The dimensions associated to the crack length and diagonal indent measurements and c) Bilogarithmic representation of crack length an apparent hardness versus the applied load and the definition of the critical point $\left(\mathrm{P}_{\mathrm{c}}, \mathrm{a}_{\mathrm{c}}\right)$ used to calculate the interfacial indentation toughness.

The straight line thus obtained is called the apparent hardness straight line by the authors. The intersection point of these two lines corresponds to the moment when the crack begins for a so-called critical load (Pc).The coordinates of the intersection point of these two lines are shown in figure.(2-c). The (Pc, ac) couple which defines the initiation of the interfacial crack is used to calculate the apparent interfacial toughness from equations (1) and (2) according to Chicot et al. [23, 24]:

$K_{c a}=0.015\left(\frac{E}{H}\right)_{i}^{\frac{1}{2}} P_{c}\left(a_{c}\right)^{-\frac{3}{2}}$

$\left(\frac{E}{H}\right)_{i}^{\frac{1}{2}}=\frac{\left(\frac{E}{H}\right)_{s}^{\frac{1}{2}}}{1+\left(\frac{H_{S}}{H_{c}}\right)^{\frac{1}{2}}}+\frac{\left(\frac{E}{H}\right)_{c}^{\frac{1}{2}}}{1+\left(\frac{H_{c}}{H_{S}}\right)^{\frac{1}{2}}}$

Whose the equation (2) has been proposed by Chicot et al. for calculating $(\mathrm{E} / \mathrm{H})_{\mathrm{i}}{ }^{1 / 2}$ and where $\mathrm{E}$ is the Young's modulus, $\mathrm{H}$ is the hardness, and the indices (s), (c) and (i) correspond respectively to the substrate (here the steel bar), to the coating (here the concrete) and to the interface.

This apparent interfacial toughness is measured to see if it can be considered as a relevant criterion for estimating the adhesion between the concrete and the steel reinforcement and to replace the conventional tests used to characterize the adhesion between the concrete and its Metal reinforcement.

\section{Results and Discussion}

A statistical or grid nanoindentation experiment involving large number of test points has shown to provide micromechanical properties of two types of concrete, SCC and VC, using 100 test points and a smaller indent spacing of $150 \mu \mathrm{m}$ as it is showed in figure 3-a). Figures(3-b) and (3-c) show the mechanical properties maps for the 28-day hydrated SCC54 matrix as an example. 
Young's modulus and hardness of self-compacting concrete (SCC62) are $49.524 \pm 22.347 \mathrm{GPa}$ and $2.002 \pm$ $2.147 \mathrm{GPa}$, respectively. However, for the Young's modulus and the hardness of self-compacting concrete (SCC54) are (47.876 \pm 24.667$) \mathrm{GPa}$ and $(1.943 \pm 2.376)$ GPa respectively, determined by the nano indentation test (figures3 and 4), are slightly lower than those of vibrated concrete (VC54) which are (49.201 \pm 25.349$) \mathrm{GPa}$ and $(1.965 \pm 2.402) \mathrm{GPa}$ having similar compressive strength. This difference is not considered significant, although this may be expected due to higher past, reduced amount of coarse aggregates and reduced overall tightening.

a) SEM image

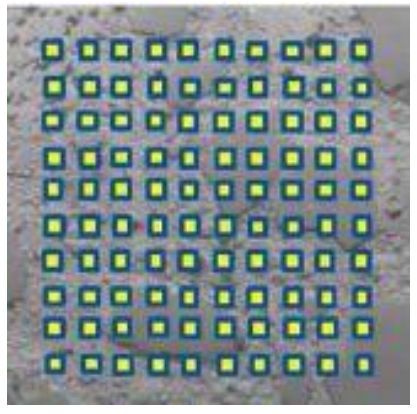

b) Hardness map

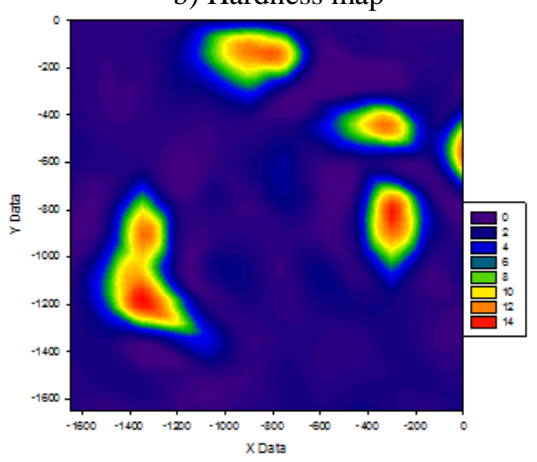

c) Young's modulus map

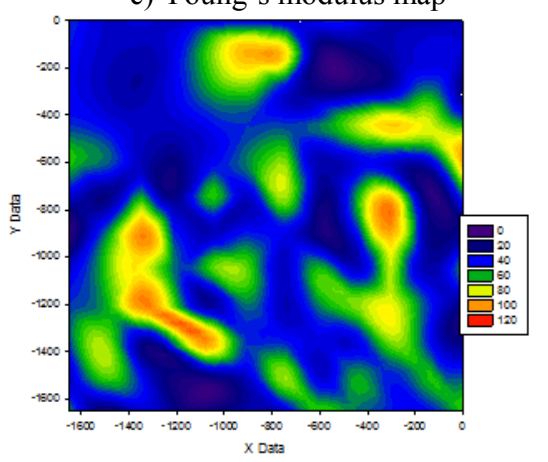

Figure 3: SEM image of the tested area (100 indents) in SCC54 matrix and corresponding mechanical properties maps for Hand $E$.

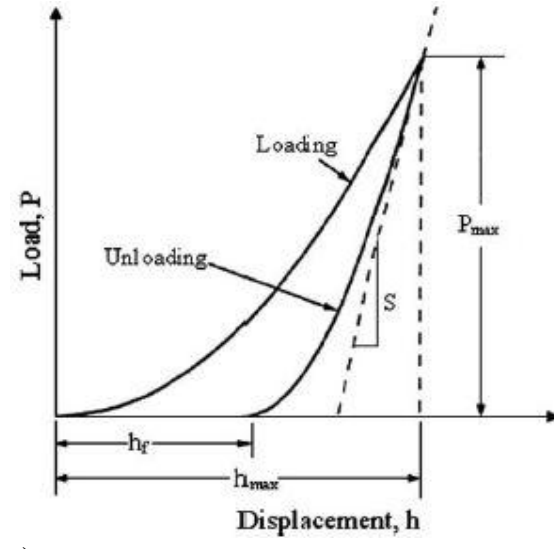

a)

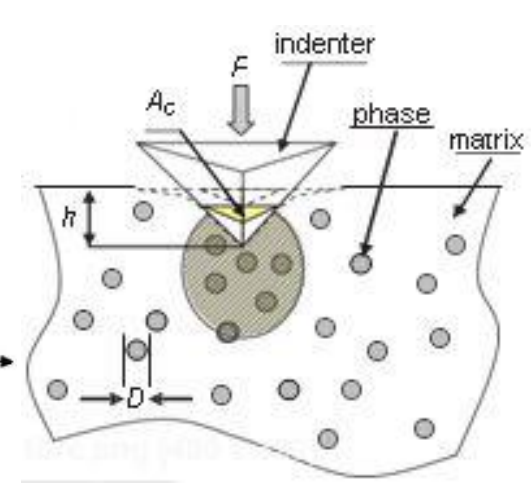

b)

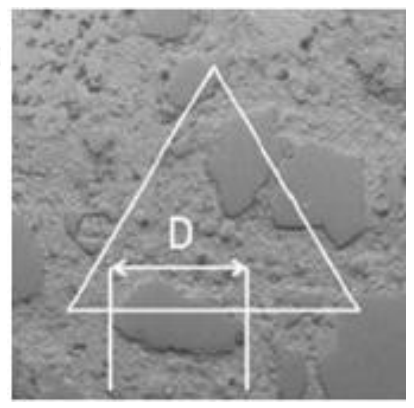

c)

$\mathrm{h}=$ depth of indentation, $\mathrm{D}=$ grain diameter in the matrix .

Figure 4: a)A typical representation of the indentation load "P" versus indentation depth" h", b)Grid indentation on a heterogeneous system where the probed microvolume (cross-hatched regions below the indenter) is larger than the characteristic length scale, $\mathrm{D}(\mathrm{h}>>\mathrm{D})$, of the interest concrete matrix,c)magnified view of cross-hatched regions below the indenter after testing: wide indent, so average measure.

In other hand, for validate the interfacial indentation test, we have complied with the following experimental conditions:

- The length of the crack (a) must be greater than the half length of the impression (d/2).

- The thickness of the coating must be at least three times (optimally five times) the half length of the impression [26].

- The test should be performed with the tip of the indenter located on, or near the interface. It is recommended that the distance between the center of the cavity and the interface be less than the half diagonal of the impression.

- The distance between the center of the impression and the edge of the sample must be greater than $3 \mathrm{~mm}$. In order to choose the range of loads to be applied to the concrete/steel interface by indentation, we carried out tests with increasing loads between 10 and $2200 \mathrm{~N}$. For low loads, only a residual impression is observed at the interface, whereas for higher loads, we observe a crack at the interface between the concrete and the steel reinforcement (figure 5-b). This crack first follows the interface then bifurcates and then propagates in the concrete for even higher loads. The applied load reaches a critical value (failure load), the separation between steel and concrete intervenes (figures 5-b, 5-c and5-d). 

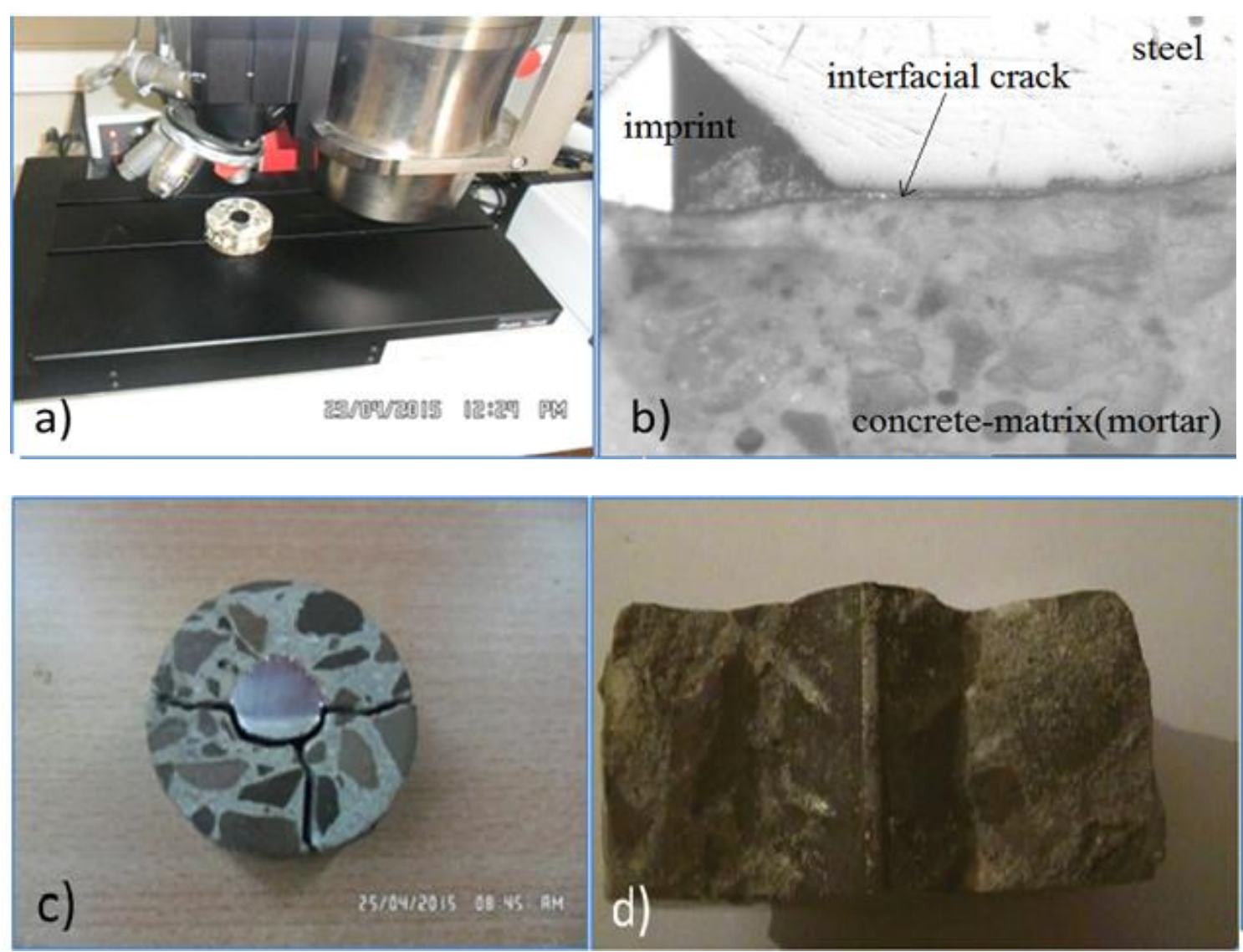

Figure 5: a- Experimental device used for the indentation test at the concrete-metal reinforcement interface, bExample of indentation at the interface showing the creation of a crack (the impression is clearly visible in the steel and little in the concrete); $\mathbf{c}$ and $\mathbf{d}$ - Indentation test performed with an applied load greater than the critical value and causing decohesion between the matrix and the steel bar.

These critical (failure) loads are $2030 \pm 15 \mathrm{~N}$ for (SCC54/Steel) and $1855 \pm 10 \mathrm{~N}$ for (VC54/Steel). In order to apply only an interfacial crack (no total decohesion), we have considered, in applying equation (1), that loads less or equal to $1200 \mathrm{~N}$, which corresponds to $65 \%$ of the critical failure load of (VC/Steel) couple.

In total, 35 interfacial indentation tests are carried out for each concrete/steel couple. Knowing the lowest failure load of the two samples $\left(\mathrm{P}_{\text {failure }}=1846 \mathrm{~N}\right)$, we selected seven loads, with a $100 \mathrm{~N}$ pitch for the interval (300 $600 \mathrm{~N}$ ) and a $200 \mathrm{~N}$ pitch for the (600 -1200 N). The curves (crack length-applied load) for each type of couple (concrete/steel) are shown in figures (6-a, 6-b and6-c).

The interfacial apparent toughness of (SCC62/Steel) and (SCC54/Steel) couples are respectively 2.53 MPa.m ${ }^{1 / 2}$ and $2.38 \mathrm{MPa} \cdot \mathrm{m}^{1 / 2}$ (table 8). The (SCC62/steel) couple has an apparent interfacial toughness about $6.72 \%$ higher than that of the (SCC54/Steel) couple. This may be related to the low water content of the SCC62 in front of that of the SCC54, ie its porosity in order to reduce the accumulation of sweat water around the reinforcement bars embedded in the structural elements. In the other hand, the interfacial apparent toughness of (SCC54/Steel) and (VC54/Steel) couples are respectively 2.38 MPa.m ${ }^{1 / 2}$ and $2.18 \mathrm{MPa} \cdot \mathrm{m}^{1 / 2}$ (table 8). The (SCC54/steel) couple has an apparent interfacial toughness about $10 \%$ higher than that of the reference couple. This can be related to the lower water content of the SCCs, and in particular to the large volume of ultrafine particles (silica fumes and calcareous fillers) introduced in order to reduce the accumulation of sweating water under the bars of reinforcement horizontally embedded in the structural elements. The porosity, clearly lower at the matrix/reinforcement interface, corresponds to a more compact structure with a smaller number of defects without visible segregation. It should also be noted for these concretes, a higher fluidity which results in a better covering of the rebar.

The results obtained with the interfacial indentation test show that for the different water to binder ratio, so different compressive strengths, and the best adhesion is attributed to the SCC with lower water to binder ratio and/or with higher compressive strength. The results obtained with the interfacial indentation test show that for the same compressive strength, the adhesion of the SCC to the steel reinforcement is higher than for the VC. On the basis of conventional tensile and flexural tests, to characterize the adhesion, it should be mentioned that 
various researchers have achieved variable or even contradictory results, but it seems nevertheless that the adhesion between the concrete and the steel reinforcement is higher for SCCs than for VCs [27, 28].

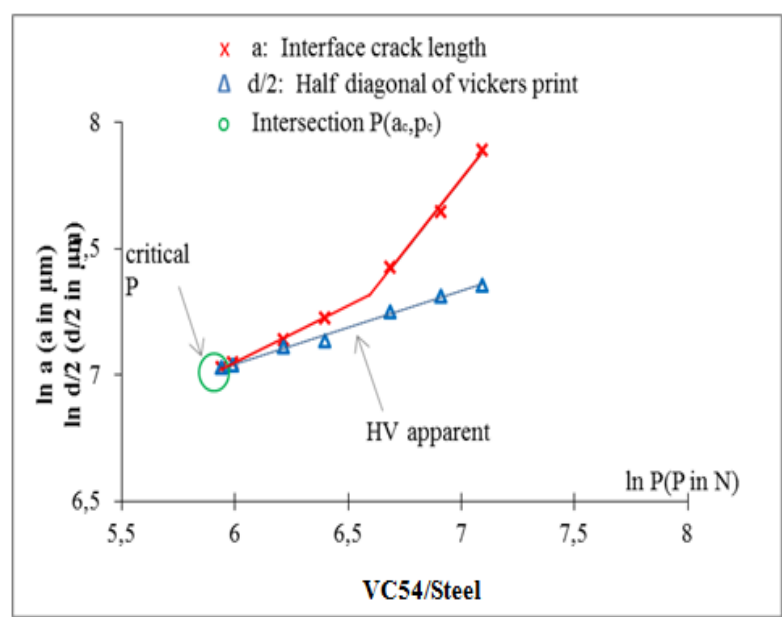

a)

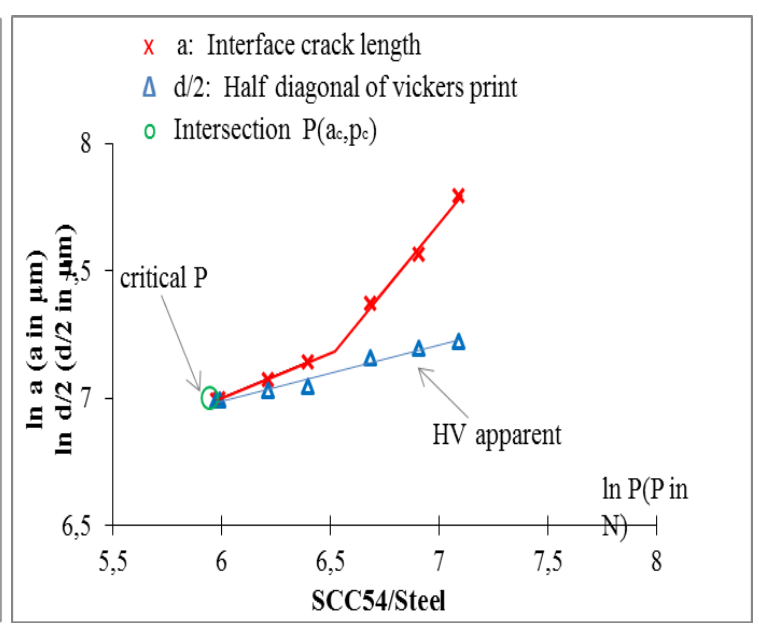

b)

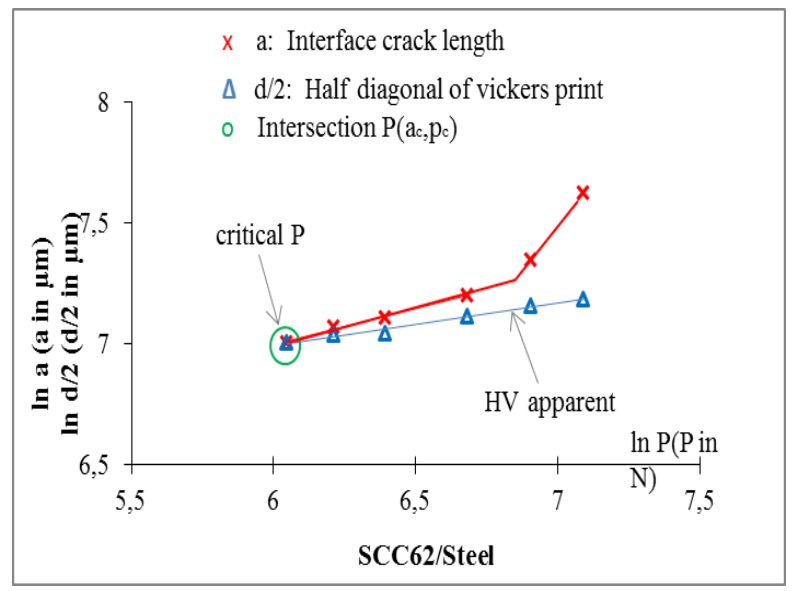

c)

Figure 6: The bi-logarithmic plots of the indentation half-diagonal, $d,(\Delta)$ and crack length, a, $(x)$ formed at the interface between the concrete and the steel reinforcement, as a function of the load, P, applied to the Vickers indenter. (a): Plotted curves for vibrated concrete/steel couple (VC54/St), (b): Plotted curves for selfcompacting concrete/steel couple (SCC54/St) and (c): Plotted curves for self-compacting concrete/steel couple (SCC62/St).

Table 8: Adhesion properties comparison

\begin{tabular}{|c|c|c|c|}
\hline Adhesion properties & VC54 & SCC54 & SCC62 \\
\hline w/b ratio & 0.36 & 0.35 & 0.33 \\
\hline w/c ratio & 0.36 & 0.47 & 0.44 \\
\hline $\mathrm{fc}_{28, \text { cyl }}[\mathrm{MPa}]$ & $53.6 \pm 1.6$ & $54.3 \pm 2.2$ & $61.7 \pm 3.0$ \\
\hline Kca $\left[\mathrm{MPam}^{1 / 2}\right]:$ IITs (This study) & 2.18 & 2.38 & 2.53 \\
\hline$\left(\tau_{\max } / \mathrm{fc}^{1 / 2}\right):$ POTs $($ Literature Valcuende and Parra [29] $)$ & 2.367 & 2.585 & $/$ \\
\hline
\end{tabular}

* Kca $\left[\mathrm{MPam}^{1 / 2}\right]$ IITs: Apparent interfacial toughness measured using Instrumented Indentation Tests.

$\left(\tau_{\max } / \mathrm{fc}^{1 / 2}\right)$ POTs: Normalized bond strength measured using Pull Out Tests.

In particular, Valcuende and Parra [29] studied the adhesion between (SCC/Steel) and (VC/Steel) couples, for different water to binder ratios (w/b), different compressive strength values and Steel bar with $16 \mathrm{~mm}$ diameter. These authors observed that the mean Normalized bond strength $\left(\tau_{\max } / \mathrm{fc}^{1 / 2}\right)$ is greater for the (SCC/Steel) couples than for the (VC/Steel) couples. For the $54 \mathrm{MPa}$ class cylinders (60 MPa cube), the difference is about 10\%:2.58 instead of 2.37, which confirms the results obtained in our study. The difference for the normalized bond strength, weighted by the compressive strength, is only 5\% according to Daoud et al. [30]. For both parameters (strength and toughness), there is therefore a good coherence of our results with those of the literature. In both cases, we find that the adhesion properties of (SCC/Steel) are better than those of (VC/Steel). 
In this study, all samples were then fractured (failed) by indentation under loads greater than those used for the interfacial indentation test. For example, for the (SCC54/Steel) sample, it has been observed that the crack begins to propagate along the (steel/concrete) interface under a progressive load and then deviates from this interface to the matrix of the concrete, which causes it to failure, followed by loss of connection between the reinforcement and the concrete once the ultimate load close to $1855 \mathrm{~N}$ has been reached. A similar trend is observed with the (SCC54/Steel) combination for a slightly higher applied load (2030 N).

To improve the resistance as well as the apparent interfacial toughness, it is essential to prevent the initiation and propagation of cracks in an effective way. The (water/binder) ratio plays an important role in restricting the appearance and then the propagation of the micro cracks, which has resulted in a significant improvement in the mechanical strength of the SCCs. The interface between the concrete and its steel reinforcement is considered the most crucial element of reinforced concrete because it establishes a connection between the two heterogeneous phases. We have observed this interface in scanning electron microscopy (SEM). The micrographs of the interfaces on the SCC-matrix and VC-matrix sides are shown in figures (7-a, 7-b).

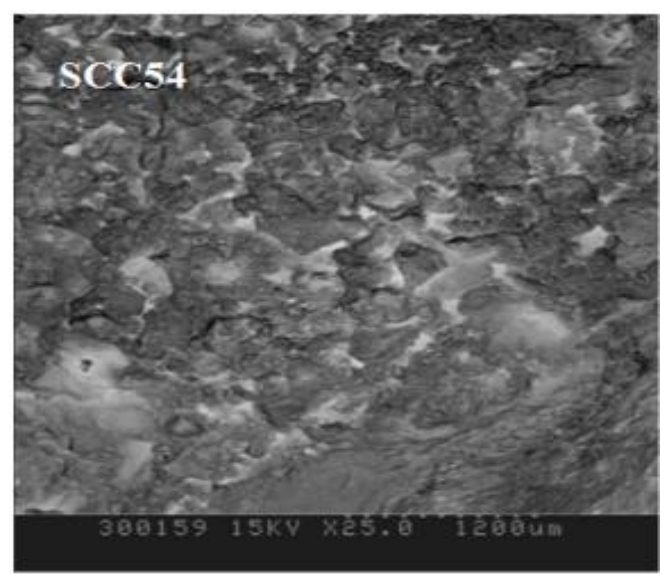

a)

*SCC: Self Compacting Concrete;

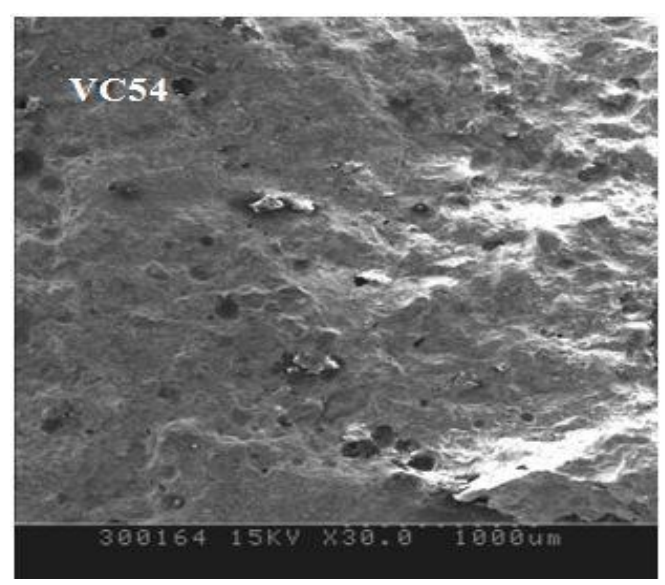

b)

Figure 7: Micrographs (SEM) obtained for the concrete interface in contact with the steel reinforcement after decohesion caused by an interfacial indentation with an applied load, $\mathrm{P}$, greater than the critical value, (a) SCC: Self Compacting Concrete; (b) VC: Vibrated Concrete.

The microstructure of the (steel/concrete) interface is a small transition zone similar to that between the cement paste and the aggregates. Figure (7-b) shows a representative area of the interfacial layer of the VC54 mixture after the steel bar has been removed. This interface in the (VC54/Steel) couple is less resistant to cracking than that of the (SCC54/Steel) couple. One of the reasons for the low performance of the latter interface is a greater porosity resulting from the inability of the cement particles to effectively cover the steel reinforcement. This phenomenon is called "wall effect". This porosity, which is greater in the interface of VC/Steel (figure.7-b) than in that of SCC/ Steel (figure 7-a), makes it less resistant to the propagation of cracks.

The weakness of this interface can be associated at the migration of water that accumulates around the steel bar and creates the porosity. The high volume ultrafine particles (silica fume, cement and calcareous fillers) contained in the interface (SCC54/Steel) effectively fill micro pores, forming a thick, non-porous, compact matrix that is more resistant to the propagation of Cracks than the VC54 matrix. Silica fume and calcareous fillers in the cementitious matrix, due to their large surface area and high surface energy, absorb a large amount of water and reduce the possibility of forming films of water. This decrease of water films in the interfacial zone decreases its porosity.

The total thickness of the coating is about $16 \mathrm{~mm}$. With reactive cement incorporated into the surface of the coating, cement hydration reactions can occur at this level, allowing the phases of the paste to integrate into the coating and give a microstructure with a more uniform transition between the matrix and the steel reinforcement. Thus, the reinforcement of the bond between the steel reinforcement and the cementitious matrix is obtained at the same time as the improvement of the resistance of this interfacial zone against cracking. Even if the thickness of the transition zone is very small compared with that of the cementitious matrix, the modification of this weak link can lead to remarkable improvements in strength, stiffness, and toughness of these cementitious composites [31]. 


\section{Conclusions}

This work deals with the use of interfacial indentation to determine the adhesion between High-Performance Self-Compacting Concretes HPSCC (SCC62 and SCC54) and their steel reinforcements, with 16mm diameter, then the influence of the water to binder ratio on this adhesion with the comparison between the HPSCC and High-Performance Vibrated Concrete(HPVC) with respect to this adhesion, when they have the same compressive strength. The experimental results yielded the following conclusions:

- There is a correlation between the apparent interfacial toughness measured by interfacial indentation tests and the normalized bond strength measured by pull-out tests of the literature. The interfacial indentation test therefore seems to be a characterization method that can be used to estimate the adhesion between the concrete and its steel reinforcement.

- The improvement of the behavior of the adhesion of High performance self-compacting concrete (HPSCC)with respect to High performance vibrated concretes (HPVC) for the same compressive strength class can be attributed to the greater quantity of ultrafine particles and higher workability, which results in a better covering of the reinforcing bars by the concrete.

- The resistance to initiation and propagation of the cracks at the interface is a function of the water/binder ratio of the concrete.

- Lower adhesion capacities of SCC were measured for decreasing water compressive strength ( $\left.\mathrm{fc}_{28, \mathrm{cyl}}\right)$. An increase of $13.62 \%$ is observed, when ( $\mathrm{fc}_{28, \mathrm{cyl}}$ ) increases from 54.3 to $61.7 \mathrm{MPa}$. This improvement can be attributed to the influence of the compressive strength $\left(\mathrm{fc}_{28, \mathrm{cyl}}\right)$ which shows that there is a close relationship between compressive strength and this adhesion.

- Due to the improvement of the apparent interfacial toughness Kca for Self Compacting Concrete (SCCs), the application of self-compacting concretes in place of the vibrated concretes (CVs) in the construction can produce significant advantages.

Acknowledgments-We would like to thank Professor N. Kherici, Dean of the Earth Sciences Faculty at Badji Mokhtar University, and all the members of this faculty for their continuous encouragement and providing us with the material and pedagogical means used in this work.

Gratitude should also be expressed to the various laboratories and especially to their managers in giving me flourishing scientific advices and helped me to carry out my various tests and which are:

- Prof. Alain IOST and Alex Montagne (Laboratory of Mechanics Surfaces and Materials Processing (MSMP) National high School of Arts and Crafts, ParisTech - Lille.

- Prof. Didier CHICOT (Laboratory of Mechanics, FRE 3723 -LML), University of Lille, Lille, France.

- Prof. Nabila MALOUFI (Laboratory of Microstructure and Materials Engineering LEM3) Metz-University of Lorraine, France.

- Prof. Hervé MUHR (Laboratory Reactions and Process Engineering - UMR 7274 - EMMAD) Nancy-University of Lorraine, France.

- Prof. Jean Pierre CHARLES (Optical Materials, Photonics and Systems Laboratory LMOPS - EA 4423) Supélec) Metz -University of Lorraine France.

\section{References}

1. A. Castel, S.J. Foster, "Bond strength between blended slag and Class F fly ash geopolymer concrete with steel reinforcement". Cem. Concr. Res.72 (2015) 48-53.

2. A.M. Diab, H.E. Elyamany, M.A. Hussein, H.M. Al Ashy, "Bond behavior and assessment of design ultimate bond stress of normal and high strength concrete". A E J. 53 (2014) 355-371.

3. Fu X., Chung D.D.L. "Improving the bond strength between steel rebar and concrete by ozone treatment of rebar and polymer addition to concrete". Cem. Concr. Res. 27 (1997) 643-648.

4. ISO 14916, Thermal Spraying-Determination of Tensile Adhesive Strength, ISO/TC 107. (1999)

5. J.C. Bony, G. Claude, S. Sorentz, "Comparaison des essais d'adhérence par flexion (beam test) et par traction (pull-out test)". Mater. Struct. 6 (1973) 395-401.

6. F. Aslani, S. Nejadi, "Bond behavior of reinforcement in conventional and self-compacting concrete", Adv. Struct. Eng. 15 (2012) 2033-2051.

7. M. Arezoumandi, J. Looney Trevor, J.S. Volz, J.J. Myers, "An Experimental Study on Bond Strength of Reinforcing Steel in Self-Consolidating Concrete"I J C S M. 6 (2012) 187-197.

8. P. Helincks, V. Boel, W. De Corte, G. De Schutter, P. Desnerck, "Structural behavior of powder- type selfcompacting concrete: Bond performance and shear capacity", Eng. Struct. 48 (2013) 121-132.

9. NF EN 197-1.Cement - Part 1: composition, specifications and conformity criteria for common cements (April 2012).

10. ACI 234, Guide for the use of silica fume in concrete. American Concrete Institute.(2006). 
11. Federal highway administration. Silica fume.US department of transportation. http://www.fhwa.dot.gov/infrastructure/materialsgrp/silica.htm.

12. EN 1097, Tests for mechanical and physical properties of aggregates - Part 6: Determination of particle density and water absorption. (2013).

13. EN 934, Admixtures for concrete, mortar and grout - Part 2: Concrete admixtures. Definitions requirements, conformity, marking and labeling. (2009).

14. CEN. NBNEN 12350 testing fresh concrete (parts 2, 5, 8, and 9). (2009/2010)

EN 12350-2, Testing fresh concrete - Part 2: Slump Test.

EN 12350-5, Testing fresh concrete - Part 5: Flow table test.

EN 12350-8, Testing fresh concrete - Part 8: Self-compacting concrete - Slump-flow test.

EN 12350-9, Testing fresh concrete Part 9: Self-compacting concrete - V-funnel test.

EN 12350-10, Testing fresh concrete Part 10: Self-compacting concrete - L-box test.

15. EFNARC, Specification and guidelines for self-compacting concrete. ISBN 0953973344. UK, 32 (2002).

16. EN 10080, Steel for the reinforcement of concrete. (2005).

17. W. Zhu, Sonebi M., Bartos P.J.M. "Bond and interfacial properties of reinforcement in self-compacting concrete". Mater. Struct. 37 (2004) 442-448.

18. I. Pop, De Schutter G., Desnerck P., Onet T. "Bond between powder type self-compacting and steel reinforcement". Const Build Mater. 41 (2013) 824-833.

19. EN 12390- 4, testing hardened concrete - Part 4: compressive strength. Specification for testing machines. (2009).

20. EN 12390-3, Testing hardened concrete - Part 3: compressive strength of test specimens. (2009).

21. F.-J. Ulm, M. Vandamme, C. Bobko, J.A. Ortega, "Statistical Indentation Techniques for Hydrated Nanocomposites: Concrete, Bone, and Shale”, J. Am. Ceram. Soc. 90 (2007) 2677-92.

22. W.C. Oliver, G.M. Pharr, "Measurement of Hardness and Elastic Modulus by Instrumented Indentation: Advances in Understanding and Refinements to Methodology," J. Mater. Res. 19 (2004) $3-20$.

23. D. Chicot, P. Démarecaux, J. Lesage, "Apparent Interface Toughness of Substrate and Coating Couples from Indentation Test". Thin Solid Films. 283 (1996) 151-157.

24. D. Chicot, G. Marot, P. Araujo, N. Horny, A. Tricoteaux, M.H. Staia, J. Lesage, "Effect of Some Thermal Treatments on Interface Adhesion Toughness of Various Thick Thermal Spray Coatings". Surf. Eng. 22 (2006) 390-398.

25. Y. Yamazaki, S. Kuga, M. Jayaprakash, "Interfacial Strength Evaluation Technique for Thermal Barrier Coated Components by Using Indentation Method". Procedia Eng.10 (2011) 845-850.

26. Y. Yamazaki, M. Arai, Y. Miyashita, H. Waki, M. Suzuki, "Determination of Interfacial Fracture Toughness of Thermal Spray Coatings by Indentation”. J. Therm. Spray Technol, 22 (2013) 1358-1365.

27. P. Desnerck, G. De Schutter, L. Taerwe, "Bond behavior of reinforcing bars in self-compacting concrete: Experimental determination by using beam tests". Mater. Struct., 43,(2010)53-62.

28. M. Sonebi, P.J.M. Bartos "Hardened SCC and its bond with reinforcements". Proceedings of RILEM international symposium on SCC, Stockholm, Sweden. (1999) 275-290.

29. M. Valcuende, C. Parra, "Bond behavior of reinforcement in self-compacting concretes". Const Build Mater. 23 (2009) 162-170.

30. A. Daoud, M. Lorrain, M. Elgonnouni. "Résistance à l'arrachement d'armatures ancrées dans du béton autoplaçant". Mater. Struct., 35 (2002) 395-401.

31. S. Mindess, J. F. Young, D. Darwin, Concrete Prentice-Hall. Englewood Cliffs, NJ, (1981) 481.

(2018); http://www.jmaterenvironsci.com 